\title{
Design of Valve Less Micropump Using Preliminary Characteristics from Fluid Flow
}

\author{
R.Devarajan, S. Mahendran, Zainal Ambri Abdul Karim, T.Nagarajan
}

\begin{abstract}
Cooling in advanced thermal systems is ever in demand. The administration of such cooling will need miniaturization of the current pumping system for small scale use. A valve less pump is one of the methods to create a small flowrate pump. The design has both the intake and exhaust in the same side. The fundamental aspect that a micropump will endure is analysed from fluid mechanics analysis, is a key in the design of the first model of the pump. The sizing and criteria of the pump is set based on fluid equations of mass, momentum and energy. A design is laid out by using computer aided design (CAD) based on the voltage frequency that will be applied to the piezomaterial. The movement of the piezo material due to current will cause the fluid to move as the material will act as a diaphragm. The design is then analysed using computational fluid dynamics (CFD) from the frequency inputs and a steady flow design is simulated. The reading of the small flowrate is analysed and a proper method of designing the valve less pump is gathered.
\end{abstract}

\section{Index Terms - CFD, Fluid Flow, Micropump}

\section{INTRODUCTION}

Microelectronics is expanding with wide demands of computing, the need to manage the thermal aspects of systems is playing a critical role in the packaging industries. Using high power density levels, computer mainframes, telecommunication equipments, supercomputers and high powered systems will increasingly require improved cooling that is not possible that traditional air-cooling or direct immersion cooling technologies. A novel cooling method with improved pumping performance is crucial in facing the growing need of the electronic markets.

The idea of micropumps have been developed by using several actuation methods, such as electromagnetic [1], piezoelectric [2],[3],[4],[5],[6],[7],[8], shape memory alloy [9], electrostatic[10],[11], and thermo-pneumatic [12] devices. Most of these micropumps have complex structures and high power consumption. On the contrary, piezoelectric

Manuscript received October 12, 2009. This work was supported in part by Universiti Malaysia Pahang. This work was supported in by the faculty of mechanical engineering, Universiti Malaysia Pahang, Malaysia.

D.Ramasamy and S.Mahendran is with Faculty of Mechanical Engineering, Universiti Malaysia Pahang, 26300 UMP, Pekan, Pahang, Malaysia (phone: +609-5492223 Fax: +609-5492244; e-mail: deva@ump.edu.my).

T.Nagarajan, Zainal Ambri Abdul Karim, is with Mechanical Engineering, Universiti Teknologi PETRONAS, Bandar Seri Iskandar, 31750 Tronoh, Perak Darul Ridzuan, Malaysia. (phone: +605-3687028, Fax:+605-3656461,email:nagarajan_t@ petronas.com.my)

actuation has advantages due to its relatively simple structure and lower power consumption.

A new type of thin, compact, and light weighed diaphragm micropump will be developed to actuate liquid by the vibration of a diaphragm from this study. The amplitude of vibration by a piezoelectric device produces an oscillating flow and alters the chamber volume by the curvature change of a diaphragm. This enables the pump to function to transfer fluids such as water or air.

A valve less pump consists of two fluid flow rectifying diffuser/nozzle elements which are connected to the inlet and outlet of a pump chamber with a flexible diaphragm. Stemme, [2] proposed the first prototype of valve less pump consisting of a circular cylindrical volume where the top side had a thin brass diaphragm to which a piezoelectric disc was fixed. Its flow rate was $15.6 \mathrm{ml} / \mathrm{min}$. Olssen et al, $[3,13]$ investigated the flow-directing properties of several diffuser elements with different lengths and opening angles for valve less micropumps. Numerical simulations were done by using the Computational Fluid Dynamics program ANSYS/Flotran. They found that a commercial micropump with a valve can be developed with central actuating as in Fig, 1. The drawback is the manufacture and installation of the valve.
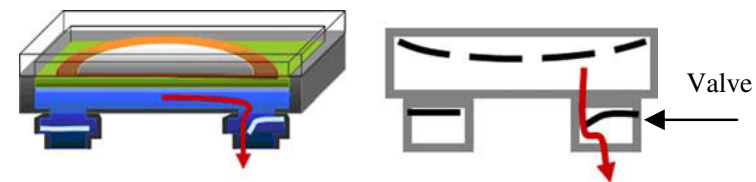

Fig. 1 View of SDMP305D micro-diaphragm pump

The target of the study is to obtain a simple three dimensional design model of the micropump without a valve using computer aided design (CAD) and tested using CFD to observe the preliminary operation of the design.

(a)
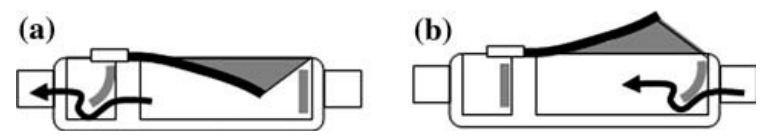

Fig. 2 Working principles of a single acting micropump

From Fig. 2, when the actuator moves downwards to decrease chamber volume, the outflow will be in one direction by moving from a inlet diffuser to an outlet diffuser. When the actuator moves upwards to increase chamber volume shown in Fig. 2(b), the fluid flowing into the pump will be in the chamber through the diverged cone, while the fluid outlet will be from the converged cone of the pump as in Fig. 3. 
Proceedings of the International MultiConference of Engineers and Computer Scientists 2010 Vol III, IMECS 2010, March 17 - 19, 2010, Hong Kong

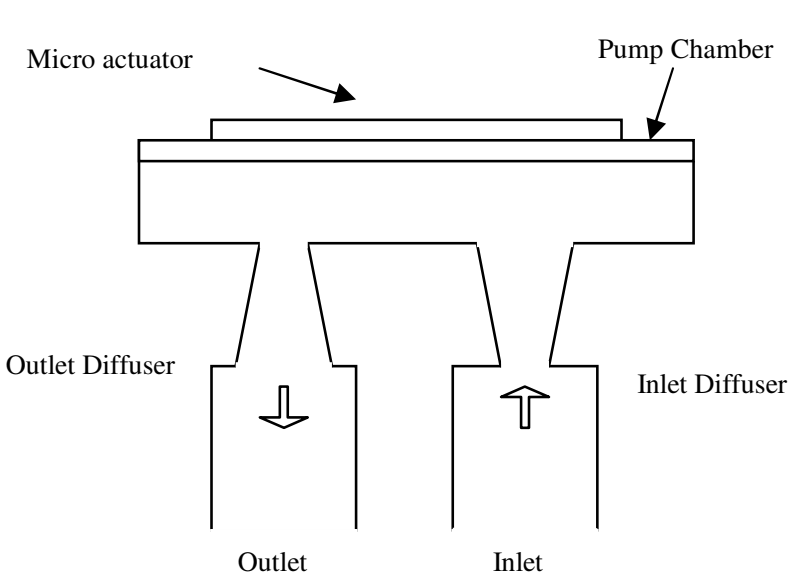

Fig. 3 Working principle of valve less micropump

Therefore, the actuating force can be enforced by its harmonic resonance of the working fluid with the vibration of a rectangular piezoelectric device, diaphragm, and two cones in the pump chamber. The design of the cones is important in terms of fluid moving into the inlet and going out. The structure of nozzle/diffuser cone is shown in Fig. 4.

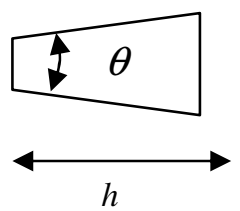

Fig. 4 Cone dimensions

Based on fluid principles it is known that, the dynamic resistance is minimum at the range of $\theta=5^{\circ}$, and the dynamic resistance is maximum when $\theta=7^{\circ}$. To start the analysis the minimum angle is used. The flow equation of clearance and pressure distribution of nozzle is given by,

$p=p_{1}-\Delta p \frac{\left(\frac{D}{h}\right)^{2}-1}{\left(\frac{D}{d}\right)^{2}-1}$

And pressure distribution of cone can be expressed as

$$
p=p_{1}-\Delta p \frac{1-\left(\frac{d}{h}\right)^{2}}{1-\left(\frac{d}{D}\right)^{2}}
$$

Where $h$, being the cross sectional diameter of the cone. The flow equation of the cone is given by the Bernoulli equation as,

$$
\frac{p_{1}}{\rho g}+\frac{v_{1}^{2}}{2 g}=\frac{v_{2}^{2}}{2 g}+\sum \zeta \frac{v_{2}^{2}}{2 g}
$$

$$
\begin{aligned}
& v_{1}=v_{2}\left(\frac{d}{D}\right)^{2} \\
& \Delta p=p_{1}-p_{2} \\
& p_{2}=0
\end{aligned}
$$

and,

$$
v_{2}=\frac{1}{\sqrt{1+\sum \zeta-\left(\frac{d}{D}\right)^{4}}} \sqrt{\frac{2 p_{1}}{\rho}}
$$

Why, $\theta=5^{\circ}$ and pipe losses estimated at, $\zeta=$ 0.0045 , the flow rate $Q$ can be expressed by,

$$
Q=v_{2} A_{2}=\frac{\pi d^{2}}{4} \frac{1}{\sqrt{1+\sum \zeta-\left(\frac{d}{D}\right)^{4}}} \sqrt{\frac{2 p_{1}}{\rho}}
$$

\section{MODELING}

From the boundary equation above and previous research of Ma et al, [14] the opening of the converged cone is set at $d$ $=0.6 \mathrm{~mm}$, and flowrate targeted to $0.6 \mathrm{ml} / \mathrm{s}$. With the two boundaries predetermined a simulation was targeted. The boundary condition is important to represent the flow in the micropump for CFD analysis to begin. The CFD software utilizes the Navier Stokes equations to solve the flow behavior.

$\frac{\partial \rho}{\partial t}+\frac{\partial}{\partial x_{k}}\left(\rho u_{k}\right)=0$

$\frac{\partial \rho u_{i}}{\partial y}+\frac{\partial}{\partial x_{k}}\left(\rho u_{i} u_{k}-\tau_{i k}\right)+\frac{\partial P}{\partial x_{i}}=S_{i}$

$\frac{\partial(\rho E)}{\partial y}+\frac{\partial}{\partial x_{k}}\left((\rho E+P) u_{k}+q_{k}-\tau_{i k} u_{i}\right)=S_{k} u_{k}+Q_{H}$

Where u is the fluid velocity, $\rho$ is the fluid density, $S_{i}$ is a mass-distributed external force per unit mass, $E$ is the total energy per unit mass, $Q_{H}$ is a heat source per unit volume, $\tau_{i k}$ is the viscous shear stress tensor and $q_{i}$ is the diffusive heat flux.

A model design is done as shown in Fig. 5 with both cones attached to form the micropump. A moving wall was targeted to oscillate as per the piezomaterial frequency and two outlets, one being an input and the other being an output is modeled in CFD, but for this analysis a steady state is assumed throughout the pump flow.

Where, 


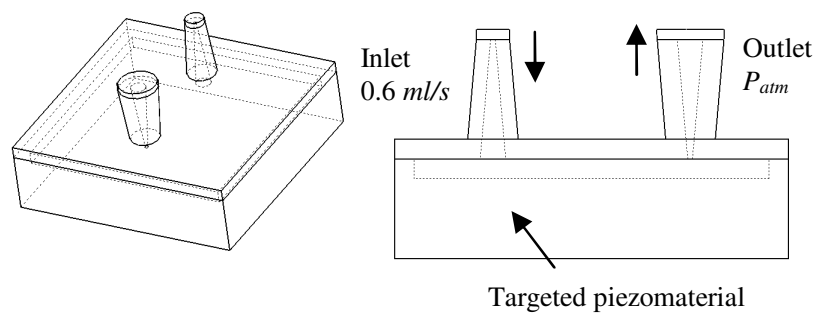

Fig. 5 Preliminary Design

\section{RESULTS}

A basic mesh is obtained from CFD, showing the computational grid that will be taken by the fluid into the micropump system. Fig. 6 shows the grid distribution in the small cavity. The spacing is done automatically by the software for the preliminary analysis to show the system functionality.

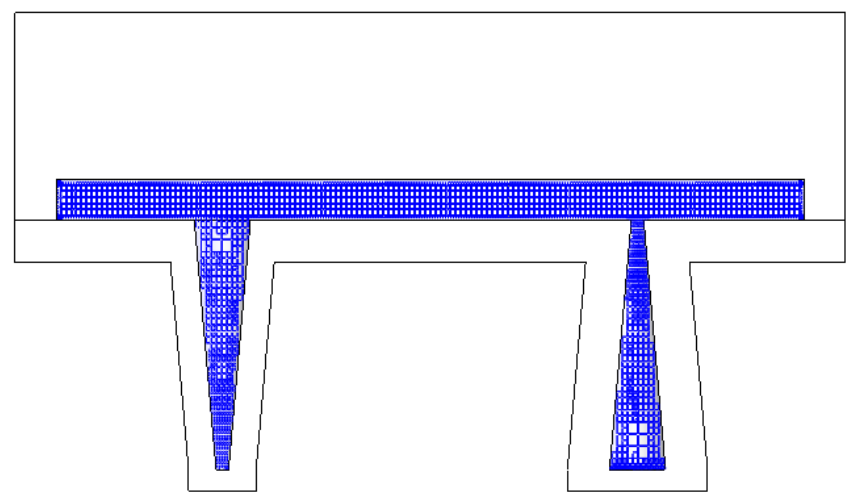

Fig. 6 Grid Spacing

Pressure and velocity results show that the pump cavity can deliver the flow as per calculations. Fig. 7 and 8 shows the respective simulation. There seem to be a small pressure buildup as the flow is moving from the inlet and exiting the outlet. The amount is small about $18 \mathrm{~Pa}$. This creates very little pressure drop to the system and is seen as an advantage to the design.

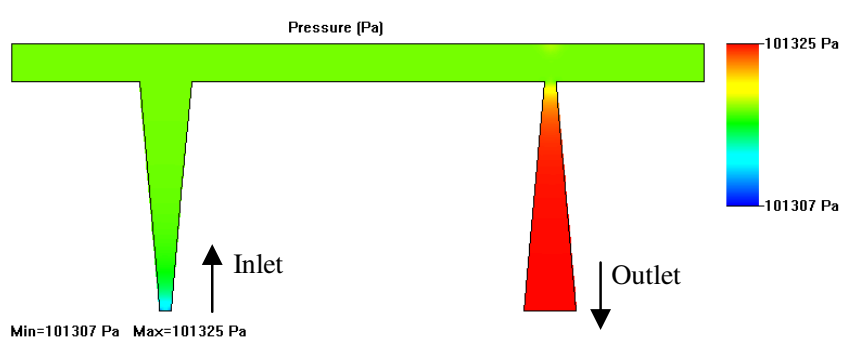

Fig. 7 Pressure Readings

For the velocity plot the converged section shows an increase in velocity. This relates to Bernoulli equation where the higher pressure region (inlet) creates a lower velocity and the lower pressure region (converged cone) create higher velocity.

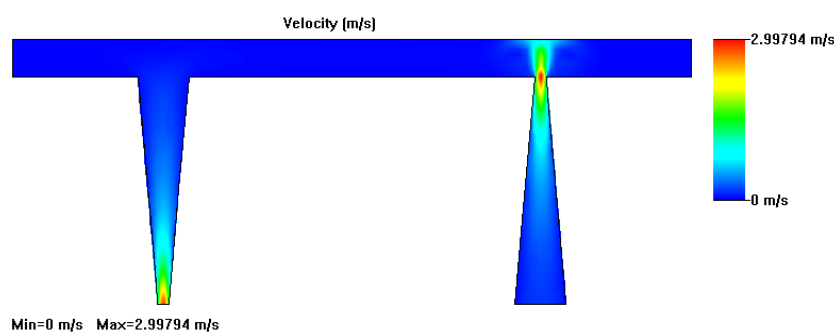

Fig. 8 Velocity Readings

The flow seems to accumulate more in the inlet cone, in the converging section. As seen in Fig. 9, the region may cause some fluids with particles to clog the inlet. Small foreign objects will also cause this inlet to be clogged if the flow is too fast. A fillet may help in the future design.

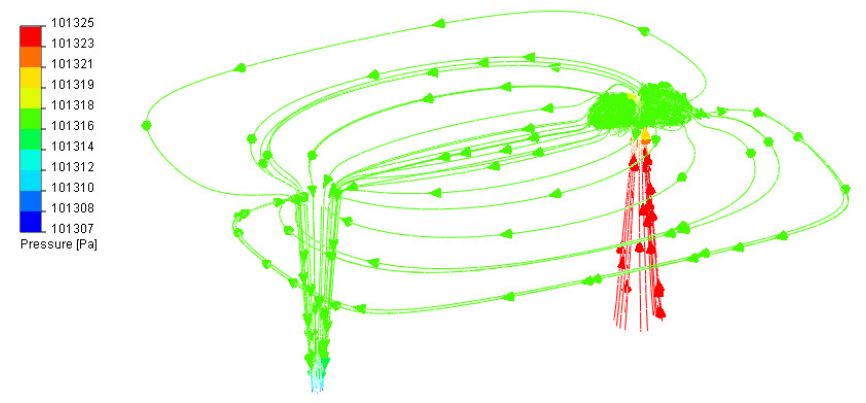

Fig. 9 Trajectories of the Flow Moving in the Pump

The other parameters that requires further investigation is on the wall, to ascertain the behavior when piezomaterial is used. The current CFD software used can only enable pressure plots and fluid flow. Hence, more elaborate models will be required to represent the wall as moving per frequency of the model.

\section{CONCLUSION}

The first model of the design is obtained from simulation studies as seen above. The design still requires many more analysis so that a final model may be arrived before fabrication for testing. The fluid flow equations from fundamental may help, but a CFD approach enables visualization with fluid properties at the micro flow level. The second challenge would be to develop the required methods to find more accurate flow speed and modeling wall movement will be required to lead to a solution.

\section{ACKNOWLEDGMENT}

D.Ramasamy would like to thank University Malaysia Pahang for sponsor and financial support for the paper.

\section{REFERENCES}

[1] Bo“hm S, Olthuis W, Bergveld P (1999). A plastic micropump constructed with conventional techniques and materials. Sens Actuators A77:223-228.

[2] Stemme E, Stemme G (1993). A valveless diffuser/nozzle-based fluid pump. Sens Actuators A39:159-167.

[3] Olsson A, Enoksson P, Stemme G, Stemme E (1995). A valve-less planar pump in silicon. In: The 8th international conference on solid-state sensors and actuators, vol 2, pp 291-294. 
Proceedings of the International MultiConference of Engineers and Computer Scientists 2010 Vol III, IMECS 2010, March 17 - 19, 2010, Hong Kong

[4] Koch M, Harris N, Evans AGR, White NM, Brunnschweiler A (1998). A novel micromachined pump based on thick-film piezoelectric actuation. Sens Actuators A70:98-103.

[5] Saggere L, Hagood NW, Roberts DC, Li HQ, Steyn JL, Turner K, Carretero JA, Yaglioglu O, Su YH, Mlcak R, Spearing SM, Breuer KS, Schmidt MA (2000). Design, fabrication, and testing of a piezoelectrically driven high flow rate micro-pump. In: Applications of ferroelectrics, proceedings of 12th IEEE international symposium, vol 1, pp 297-300.

[6] Suzuki H, Yoneyama R (2003). Integrated microfluidic system with electrochemically actuated on-chip pumps and valves. Sens Actuators B6:38-45.

[7] Yang KS, Chen IY, Chien KH, Wang CC (2004). A numerical study of the nozzle/diffuser micro-pump. In: International conference on MEMS, NANO and smart systems, pp 104-109.

[8] Li B, Chen Q, Lee DG, Woolman J, Carman GP (2005). Development of large flow rate, robust, passive micro check valves for compact piezoelectrically actuated pumps. Sens Actuators A117:325-330.

[9] Benard WL, Kahn H, Heuer AH, Huff MA (1998). Thin-film shapememory alloy actuated micropumps. J Microelectromech Syst 7:245-251.

[10] Francais O, Dufour I, Sarraute E (1997). Analytical static modeling and optimization of electrostatic micropumps. J Micromech Microeng $7: 183-185$.

[11] Teymoori MM, Abbaspour-Sani E (2005). Design and simulation of a novel electrostatic peristaltic micromachined pump for drug delivery applications. Sens Actuators 117:222-229.

[12] Takao H, Miyamura K, Ebi H, Ashiki M, Sawada K, Ishida M (2003). A thermo-pneumatic in-channel microvalve with PDMS diaphragm for integrated blood examination system on silicon. In: The 12th international conference on solid-state sensors, actuators and Microsystems, vol 1, pp 139-142.

[13] Olsson A, Stemme G, Stemme E (2000). Numerical and experimental studies of flat-walled diffuser elements for valve-less micropumps. Sens Actuators A84:165-175.

[14] Ma HK, Hou BR, Wu HY, Lin CY, Gao JJ, Kau M.C. (2008). Development and application of a diaphragm micro-pump with piezoelectric device, Microsyst Technol (2008) 14:1001-1007 Springer-Verlag 2007. 